\title{
4
}

\section{DESAFIOS DA FORMAÇÃO PROFISSIONAL CRÍTICA EM TEMPOS DE PANDEMIA, NEOLIBERALISMO E CONSERVADORISMO}

\author{
Challenges of critical professional formation in times of pandemic, neoliberalism and \\ conservatism
}

\author{
Priscila Fernanda Gonçalves Cardoso* \\ https://orcid.org/0000-0002-3524-7623
}

Giovanna Canêo**

https://orcid.org/0000-0001-8003-5542

\begin{abstract}
RESUMO
O objetivo deste artigo é elucidar a formação profissional crítica em Serviço Social perante os desafios postos pelo neoliberalismo, a radicalização do conservadorismo e o atual momento da Pandemia de COVID-19. Para tanto, a partir de revisão bibliográfica, traz reflexões numa perspectiva sócio-histórica acerca da formação em Serviço Social, bem como, apresenta dados atuais que demonstram o processo de precarização ao qual a educação está submetida desde a contrarreforma do Estado brasileiro até a atualidade com a dramática situação vivenciada no país diante da Pandemia. Ressalta, por fim, a importância da reafirmação de um projeto de formação crítica que defenda os direitos humanos e tenha como embasamento a perspectiva emancipatória, como resistência ao avanço do pensamento conservador na atualidade e a todos os retrocessos na educação superior no Brasil.
\end{abstract}

\section{PALAVRAS-CHAVE}

Formação Profissional. Serviço Social. Pandemia de COVID-19. Conservadorismo.

\section{ABSTRACT}

The objective of this article is to elucidate the critical professional formation in Social Work in face of the challenges posed by neoliberalism, the radicalization of conservatism and the current moment of the COVID19 Pandemic. For this, based on a bibliographic review, it brings reflections from a socio-historical perspective about the formation of Social Work, as well as, presents current data that demonstrate the process of precariousness to which education is submitted since the counter-reform of the Brazilian State until the present time with the dramatic situation experienced in the country in face of the Pandemic. Finally, it

\footnotetext{
* Assistente Social. Doutora em Serviço Social. Professora associada da Universidade Federal de São Paulo/Baixada Santista no curso de Serviço Social e no Programa de Pós-graduação em Serviço Social e Políticas Sociais. (UNIFESP, Santos, Brasil). Rua Silva Jardim, no. 136, Vila Matias, Santos (SP), CEP.: 11015-020. E-mail: pcardoso@unifesp.br.

** Assistente Social. Mestra em Serviço Social e Políticas Sociais pela Universidade Federal de São Paulo. (UNIFESP, Santos, Brasil). Rua Silva Jardim, no. 136, Vila Matias, Santos (SP), CEP.: 11015-020. E-mail: gicaneo80@gmail.com.
}

DOI 10.22422/temporalis.2021v21n41p70-86

(cc) BY Commons Atribuição 4.0 Internacional (https://creativecommons.org/licenses/by/4.o/deed.pt_BR), que permite copiar e redistribuir o material em qualquer suporte ou formato, bem como adaptar, transformar e criar a partir deste material para qualquer fim, mesmo que comercial. O licenciante não pode revogar estes direitos desde que você respeite os termos da licença. 


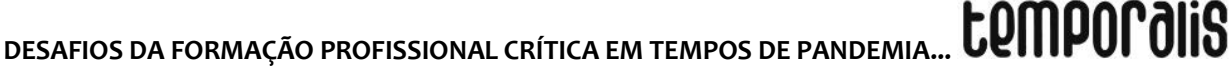

emphasizes the importance of reaffirming a critical formation project that defends human rights and is based on an emancipatory perspective, as a resistance to the advance of conservative thought today and all the setbacks in higher education in Brazil.

\section{KEYWORDS}

Professional Formation. Social Work. COVID-19 Pandemic. Conservatism.

\section{INTRODUÇÃO}

$\mathrm{O}$ presente artigo objetiva elencar os desafios da efetivação da formação crítica hegemônica no Serviço Social desde o currículo mínimo de 1982, frente a atual crise econômica e a pandemia mundial da COVID-19. É fruto de uma pesquisa bibliográfica (com a consulta de artigos, livros, textos acadêmicos, bem como bancos de dados e materiais midiáticos circunscrito ao período da referida Pandemia).

O artigo está dividido em dois tópicos. O primeiro, intitulado: "Formação crítica em Serviço Social, neoliberalismo e conservadorismo", retoma as características centrais do projeto de formação crítica do Serviço Social, elencando aspectos importantes que marcaram o currículo mínimo de 1982 e as diretrizes curriculares de 1996. Ressalta, ainda, os desafios para a formação frente a conjuntura neoliberal e o conservadorismo. As/os autoras/es base foram: Barroco (2008), Boschetti (2015), Dahmer (2018), lamamoto (2014), Melo e Cardoso (2021), Netto (2010) e Sousa, Santos e Cardoso (2013).

O segundo tópico denominado: "Os desafios da efetivação de um projeto de formação profissional crítico em Serviço Social na atual conjuntura pandêmica" visa apresentar as problemáticas atuais a serem enfrentadas na afirmação do projeto crítico de formação em Serviço Social no Brasil, frente a atualidade pandêmica e a conjuntura social, econômica e política no país. As/os autoras/es que fomentaram a discussão foram: Antunes (2018), Farage (2021) e Yazbek, Raichelis e Sant'ana (2020).

Importante destacar que a formação acadêmico-profissional ${ }^{2}$ é um dos espaços de disputa por hegemonia de um projeto profissional. É nesse momento que se inicia a formação da/o futura/o profissional que viverá cotidianamente os dilemas e desafios colocados a essa

\footnotetext{
${ }^{1}$ [...] Na pesquisa bibliográfica as fontes são constituídas sobretudo por material impresso localizado nas bibliotecas, na pesquisa documental, as fontes são muito mais diversificadas e dispersas. Há, de um lado, os documentos de primeira mão, que não receberam nenhum tratamento analítico. Nesta categoria estão os documentos conservados em arquivos de órgãos públicos e instituições privadas, tais como associações científicas, igrejas, sindicatos, partidos políticos etc. Incluem-se aqui inúmeros outros documentos como cartas pessoais, diários, fotografias, gravações, memorandos, regulamentos, ofícios, boletins etc. De outro lado, há os documentos de segunda mão, que de alguma forma já foram analisados, tais como: relatórios de pesquisa, relatórios de empresas, tabelas estatísticas etc. Nem sempre fica clara a distinção entre a pesquisa bibliográfica e a documental, já que, a rigor, as fontes bibliográficas nada mais são do que documentos impressos para determinado público. Além do mais, boa parte das fontes usualmente consultada nas pesquisas documentais, tais como jornais, boletins e folhetos, pode ser tratada como fontes bibliográficas (GIL, 2002, p. 46).

${ }^{2}$ Ao falarmos formação acadêmico-profissional, estamos nos referindo a formação que ocorre a partir da graduação em Serviço Social, não tendo ali seu fim. No entanto, para efeitos deste artigo, focaremos no projeto de formação que diz respeito a graduação em Serviço Social.
}

Temporalis, Brasília (DF), ano 21, n. 41, p. 70-86, jan./jun. 2021. | ISSN 2238-1856 
profissão. Assim, a preparação dessa/e profissional exige total atenção e compromisso político e pedagógico, pois, temos aí a disputa da direção social dessa profissão.

Ao falarmos dessa formação profissional, há que se lembrar que não se trata de um mecanismo tecnicista, mas sim do desenvolvimento de competências éticas, teóricas e técnicas que possibilitem à/ao profissional uma intervenção qualificada diante das necessárias respostas às expressões da questão social. Mas, além de uma formação profissional, ocorre na graduação, também, uma formação que envolve o questionamento de valores, a construção de uma postura ética no mundo e o compromisso político com a sociedade.

Neste sentido, entendemos como fundamental pensar os desafios postos na atualidade à esta formação, diante dos ataques à educação, a radicalização do conservadorismo e a Pandemia de COVID-19. Esperamos trazer neste artigo, algumas reflexões que nos ajudem a construir estratégias coletivas para o enfrentamento a tais desafios.

\section{FORMAÇÃO CRÍTICA EM SERVIÇO SOCIAL, NEOLIBERALISMO E CONSERVADORISMO}

Ao nos remetermos a ideia de uma formação crítica hegemônica na atualidade, estamos nos referindo a um projeto de profissão que desde o final da década de 1970 disputa tal hegemonia consolidando-se fortemente nos anos 1990. Projeto este que rompe com a perspectiva conservadora na profissão, numa importante inflexão à uma perspectiva emancipatória, tendo por base os fundamentos da tradição marxista.

Tal inflexão ocorre num momento de lutas e posicionamentos da sociedade e da categoria contra a ditadura militar, durante os anos de 1960 e 1970, intensificando-se no processo de "abertura democrática", com o aprofundamento das lutas populares e o envolvimento de muitas/os profissionais e estudantes nos movimentos sociais. Expressa-se, então, nesse período, a aproximação do Serviço Social com outras áreas do conhecimento, com a força da militância e com o marxismo.

Assim, em 1982, foi aprovado pelo Ministério da Educação (MEC) o currículo mínimo, proposto pela então ABESS3 em 1979, que teve o importante papel de articuladora das escolas de Serviço Social em âmbito nacional. Antecederam esse currículo, outros três (1953, 1964 e 1970), todos marcados por uma perspectiva conservadora, sendo, portanto, o currículo de 1982, a primeira expressão de um projeto crítico de formação no Serviço Social brasileiro.

Como marca desse processo, podemos salientar: 1) A apropriação da realidade na visão marxista, ao pensar o Serviço Social na luta de classes, não como uma profissão endógena, mas inserida no processo de produção e reprodução social. 2) A busca em romper com as perspectivas tecnicistas na formação em Serviço Social. 3) A compreensão de como o Serviço Social está inserido na divisão sociotécnica do trabalho, e o seu significado social, a partir da obra de lamamoto e Carvalho (1996) em 1982, que será amadurecida e aprofundada nas diretrizes curriculares de 1996. 4) A busca pelo fortalecimento de uma

\footnotetext{
${ }^{3}$ Associação Brasileira de Escolas de Serviço Social (ABESS), a atual Associação Brasileira de Ensino e Pesquisa em Serviço Social (ABEPSS).
}

Temporalis, Brasília (DF), ano 21, n. 41, p. 70-86, jan./jun. 2021. | ISSN 2238-1856 


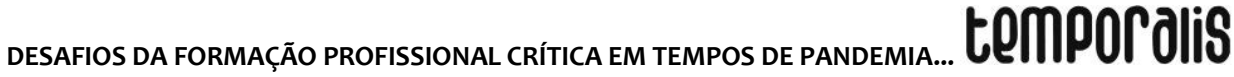

identidade profissional pautada na competência teórico-prática, a qual compreende a teoria e a prática como uma unidade.

Além deste currículo, a perspectiva emancipatória se expressa, nesta mesma década no Código de Ética de 1986, demarcando a tomada de direção intelectual e política desta perspectiva na categoria. Suas revisões na década seguinte, traduzem o amadurecimento deste projeto profissional na realização da autocrítica necessária para mudanças substanciais, porém sem uma ruptura com o projeto hegemônico emancipatório.

Os anos 1990 representaram a entrada do Brasil no neoliberalismo ${ }^{4}$, e nesse cenário expressaram-se diferentes ações governamentais 5 . O neoliberalismo traz consigo uma lógica mercadológica, que resulta na precarização das relações de trabalho, na privatização do setor público, no desmonte de políticas sociais e no enxugamento de recursos destinados à educação e à saúde públicas.

Dentro dessa lógica mercadológica, em 1996, foi promulgada a Lei de Diretrizes e Bases da educação (LDB), a qual implantou: o exame nacional de curso, os mestrados profissionalizantes, a substituição dos currículos mínimos por diretrizes, e deu abertura ao ensino à distância em todos os níveis. Medidas que representaram a diversificação e massificação do ensino superior (BOSCHETTI, 2015), voltados aos interesses do capital, num processo chamado pela referida autora de contrarreforma da educação.

Assim, os currículos mínimos são substituídos pelas diretrizes curriculares, processo de mudança no qual se permuta as ementas obrigatórias das disciplinas para: "[...] tópicos de estudos com caráter não obrigatório, a definição de competências e habilidades técnicooperativas" (IAMAMOTO, 2014, p. 615).

As atuais diretrizes gerais para o Serviço Social ${ }^{6}$ apresentaram grandes avanços, como: a) o amadurecimento da compreensão do significado social da profissão, b) a alteração da fragmentação da Teoria, Método e História para uma articulação essencial no trato dos conteúdos, através de uma perspectiva de totalidade evidenciada na disciplina de Fundamentos Histórico, Teórico e Metodológicos do Serviço Social (SOUSA; SANTOS; (ARDOSO, 2013), c) a compreensão da necessidade de temas transversais a todas as unidades curriculares, tais como: o método em Marx, a pesquisa, a ética profissional e a dimensão técnico-operativa; d) o aprofundamento nas repostas da profissão diante da

\footnotetext{
${ }^{4}$ Um conjunto de medidas políticas e econômicas que defendem o enxugamento das intervenções do Estado na economia, com o livre comércio, a partir dos princípios liberais, ganhando hegemonia no mundo a partir dos anos 1980. "O neoliberalismo é em primeiro lugar uma teoria das práticas político-econômicas que propõe que o bem-estar humano pode ser mais bem promovido liberando-se as liberdades e capacidades empreendedoras individuais no âmbito de uma estrutura institucional caracterizada por sólidos direitos a propriedade privada, livres mercados e livre comércio. O papel do Estado é criar e preservar uma estrutura institucional apropriada a essas práticas." (HARVEY, 2012, p. 12).

${ }^{5}$ Os governos petistas mantiveram um projeto expresso pela tentativa de conciliação de classes, já posteriormente ao golpe, marcado pelo impeachment da presidenta Dilma Rousseff em 2016, adentra-se na busca da efetivação de uma agenda neoliberal de barbárie com uma articulação com o conservadorismo, questão que será abordada mais à frente nesse primeiro tópico do artigo.

${ }^{6}$ As diretrizes curriculares foram constituídas a partir do currículo mínimo aprovado em Assembleia extraordinária de 1996 proposto pela antiga ABESS (ASSOCIAÇÃO BRASILEIRA DE ENSINO E PESQUISA EM SERVIÇO SOCIAL, 2019), sendo aprovadas, no entanto, apenas em 2004, mas, sendo conhecidas na profissão por Diretrizes Curriculares de 1996, diante do reconhecimento político do documento da entidade.
} 
conjuntura social, econômica e política e e) a consolidação do direcionamento de um projeto de profissão vinculado às demandas da classe trabalhadora (ASSOCIAÇÃO BRASILEIRA DE ENSINO E PESQUISA EM SERVIÇO SOCIAL, 2019).

Todos esses elementos representaram um amadurecimento do Serviço Social na incorporação do pensamento de $\operatorname{Marx}^{7}$ (e consequentemente do método materialistahistórico dialético) como base para a formação profissional e para a análise do trabalho profissional inserido no processo contraditório das relações sociais. A superação dessas fragilidades teóricas representou um passo importante para a categoria na apreensão de homem, mundo e sociedade e, sobretudo como subsídio na afirmação da perspectiva emancipatória como forma de resistência ao pensamento conservador, na busca de uma formação profissional crítica e de qualidade.

Trata-se, portanto, de um projeto contra hegemônico em pleno auge do neoliberalismo e da implantação de uma política educacional totalmente comprometida com os interesses do capital. Residia já em sua gênese uma série de desafios a serem enfrentados, sobretudo em sua materialização nas Unidades de Formação Acadêmicas - UFAs, diante da realidade em cada instituição de ensino.

Passados quase vinte anos da aprovação das diretrizes, os desafios, infelizmente só se ampliaram. Tivemos o aprofundamento da política neoliberal nas décadas subsequentes e, nos últimos dez anos um duro processo de radicalização do conservadorismo em nível mundial, com características bem peculiares no Brasil.

Na atualidade, o Brasil está vivenciando um leque de retrocessos políticos e econômicos, que afetam diretamente as condições de vida da classe trabalhadora. O avanço da extrema-direita no país repercutiu em políticas mercadológicas como consequência direta da efetivação de uma agenda neoliberal. Nesse sentido, as ações governamentais atuais caminham para uma ofensiva reestruturação do capital, marcada pela: "[...] redução do papel do Estado na regulação das relações econômicas, mercantilização de serviços públicos, competitividade e individualismo" (BOSCHETTI, 2015, p. 639).

Nesse processo de barbárie, crescem os níveis de desigualdade social e a questão social metamorfea-se, com novas roupagens. Realidade que evidencia o aprofundamento de suas expressões como: a precarização das relações de trabalho, o desemprego estrutural, o aumento da pobreza extrema, o achatamento salarial (com mínimas ou até inexistentes

\footnotetext{
7 Marx direciona suas pesquisas na análise concreta da sociedade burguesa, no período de transição do feudalismo ao capitalismo, do século XVIII ao XIX, na Europa Ocidental. Segundo Netto (2011b), pode-se compreender como o "[...] problema central da pesquisa marxiana a gênese, a consolidação, o desenvolvimento e as condições de crise da sociedade burguesa, fundada no modo de produção capitalista" (NETTO, 2011b, p.17, grifo do autor). Engels (2008) retrata que: “A concepção materialista da história parte da tese de que a produção, e com ela a troca dos produtos, é a base de toda a ordem social; de que em todas as sociedades que desfilam pela história, a distribuição dos produtos, e juntamente com ela a divisão social dos homens em classes ou camadas, é determinada pelo que a sociedade produz e como produz pelo modo de trocar os seus produtos" (ENGELS, 2008, p.91). Destaca-se que a autora lamamoto em 1982 foi pioneira ao realizar uma análise de totalidade do trabalho profissional da/o assistente social a partir da incorporação do método materialista-histórico-dialético.
} 


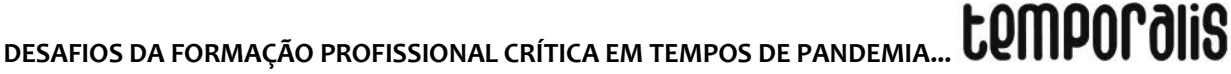

garantias trabalhistas), cada vez maior a dificuldade no acesso aos direitos fundamentais à vida como: a alimentação, moradia, lazer e educação. Realidade resultante de uma cultura ideológica de banalização da vida humana, na qual o capital impregna todos os espaços e esferas da vida social (IAMAMOTO, 2010).

Destaca-se que na atual agenda neoliberal, o Estado progressivamente limita sua intervenção na esfera social, designando a partir da ampliação do terceiro setor a responsabilidade frente às manifestações da questão social. Esta lógica resulta no desmonte das políticas públicas e ataque aos direitos sociais com grandes e progressivos cortes e contingenciamento de gastos e recursos fornecidos pelo governo federal para setores/instituições como: a previdência social, a assistência social, o Sistema único de Saúde - SUS e a educação pública.

Ressalta-se que a interferência da lógica mercadológica na educação brasileira é fruto direto da mundialização do capital e da ampliação da exigência de seguir os modelos impostos pelo Banco Mundial, pela Organização Mundial do Comércio e pelo Fundo Monetário Internacional, desencadeando-se a contrarreforma no ensino superior e criando-se uma cultura na sociedade de uma nova concepção de universidade. Em 1999, a partir do Protocolo de Bolonha é proposto um projeto de reorganização do ensino superior na Europa, com alteração estrutural num aligeiramento da formação, com caráter competitivo e sujeito às determinações do mercado (BOSCHETTI, 2015).

Essa face político-cultural compreende que uma universidade modelo deveria ter um padrão de mínimo custo (para maximizar os lucros), rápida (com cursos com duração cada vez menores), e de autofinanciamento (subsidiado e proporcionado para as elites), com uma estrutura desenvolvida para atender a expansão e a acumulação do capital, precipuamente frente a crises econômico-financeiras do capitalismo (BOSCHETTI, 2015).

A partir desse processo de ensino voltado ao mercado, a formação acadêmico-profissional em Serviço Social apresenta transformações na atualidade, como:

1) A expansão desenfreada e exponencial de vagas em instituições privadas de ensino à distância com recurso público. Segundo Dahmer (2018), a partir de uma pesquisa realizada pelo INEP em 2015, o setor privado apresentou um crescimento de 473,58\%, de 1.059 .163 em 1995, para 6.075.152 matrículas no ano de 2015, enquanto o setor público cresceu apenas $178,66 \%$ no mesmo período, de 700.540 para 1.952.145 matrículas. Esse predomínio de instituições privadas coloca em questão a tríade: ensino-pesquisa-extensão como alicerces da formação, haja vista serem essenciais numa instituição universitária. Traz ainda, o aligeiramento da formação, com o expansionismo superficial de cursos no ensino superior.

2) A precarização do trabalho docente com a expansão da contratação temporária, o rebaixamento salarial, o trabalho intensificado com um exacerbado número de orientandos, elevada carga hora/aula e aumento da proporção estudantes-professor. E, ainda, a limitação na autonomia profissional do/a docente na organização/estruturação das disciplinas, com pacotes previamente determinados por empresas que abrangem a bibliografia e o conteúdo a serem ministrados em sala de aula. 
Salienta-se, que além dos elementos supracitados do neoliberalismo, no Brasil, a partir do golpe de $2016^{8}$, e mais especificamente nas eleições de 2018, expressou-se a articulação entre o projeto neoliberal em curso e o conservadorismo9. Segundo Barroco (2015): "[...] o conservadorismo se reatualizou incorporando princípios econômicos do neoliberalismo, sem abrir mão do seu ideário e do seu modo específico de compreender a realidade" (BARROCO, 2015, p. 624).

\begin{abstract}
Nesses termos, no lapso de mais de um século de nossa história, deparamo-nos com as manifestações atuais do conservadorismo no Brasil que expressam nitidamente os elementos centrais desse pensamento na sua origem: a defesa das tradições e hierarquizações, a compreensão da necessidade das desigualdades sociais como fonte de harmonia e da disciplina e autoridade como estratégias essenciais para a manutenção do bem comum, bem como, a negação da ciência em nome da vivência/experiência (MELO; CARDOSO, 2021, p. 104-105).
\end{abstract}

Podemos afirmar que, atualmente, o pensamento conservador é elemento imprescindível da reprodução do capital, pois se constitui como ponto central na manutenção da sociedade capitalista, e apresenta como fundamento principal a moralização da questão social, pois, para:

[...] os ideólogos conservadores laicos, as manifestações da questão social (acentuada desigualdade econômico-social, desemprego, fome, doenças, penúria, desproteção na velhice, desamparo frente a conjunturas econômicas adversas etc.) passam a ser vistas como o desdobramento, na sociedade moderna (leia-se: burguesa), de características inelimináveis de toda e qualquer ordem social (NETTO, 2010, p. 5).

Ao pensarmos a profissão nesse contexto, é mais do que fundamental afirmarmos esse projeto de formação crítico e lutar por condições objetivas de sua realização nas UFAs pelo Brasil. É mister lembrar que a concepção neoliberal de Estado está presente na atuação de muitas/os profissionais e que, o conservadorismo nunca esteve morto no seio desta categoria. A existência da hegemonia de um projeto profissional crítico e emancipatório, não eliminou (e nem eliminará) a existência de perspectivas conservadoras.

Conforme retratado por Netto (2011a) os valores conservadores nunca deixaram de permear a formação e o trabalho profissional, uma vez que o Serviço Social não está dissociado da conjuntura social e política da sociedade. Destarte, nesse processo sempre existiu a dialética da convivência entre o pensamento conservador e a perspectiva emancipatória.

Todos esses elementos da atualidade somados ao avanço do conservadorismo na formação profissional e na categoria expressam o risco de um retrocesso diante das lutas históricas das entidades em busca de uma formação profissional crítica e com visão de totalidade. É necessário desvendar todas as facetas desse conservadorismo, de todos os desafios da efetivação da formação crítica atualmente, e aprofundar-se no estudo da construção sócio-histórica da formação profissional como embasamento ético-político de

\footnotetext{
${ }^{8}$ O golpe de 2016 representa o impeachment da presidenta eleita da época Dilma Rousseff.

9 Destaca-se que a gênese do pensamento conservador surge como resposta às transformações ocorridas na Revolução Francesa, que teve como figura central o inglês Edmund Burke, com críticas à democracia e defesa à manutenção da ordem, da propriedade privada, da família tradicional e das instituições como: A igreja e o Estado (MELO; CARDOSO, 2021).
}

Temporalis, Brasília (DF), ano 21, n. 41, p. 70-86, jan./jun. 2021. | ISSN 2238-1856 


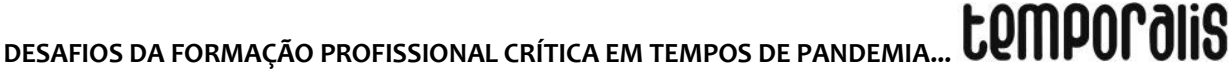

resistência. Trata-se, portanto, de uma luta constante por tal hegemonia e da necessária reafirmação deste projeto em nossas ações cotidianas, bem como, dos posicionamentos das entidades da categoria (Conselho Federal de Serviço Social e Conselho Regional de Serviço Social - conjunto (CFESS/CRESS), Associação Brasileira de Ensino e Pesquisa em Serviço Social (ABEPSS) e Executiva Nacional de estudantes de Serviço Social (ENESSO)).

\title{
OS DESAFIOS DA EFETIVAÇÃO DE UM PROJETO DE FORMAÇÃO PROFISSIONAL CRÍTICO EM SERVIÇO SOCIAL NA ATUAL CONJUNTURA PANDÊMICA
}

Desde pelo menos 2018, o cenário marcado por desigualdades sociais se agudiza, sobretudo pela crise política no país que radicaliza as tendências já presentes em todo o mundo com o avanço da efetivação da agenda neoliberal e da radicalização do pensamento conservador.

\begin{abstract}
Esse encadeamento sucessivo de crises do capital se deve ao agravamento de todas as contradições do capitalismo na atual conjuntura de crise do sistema imperialista. Tendências de queda da taxa de lucro, de superprodução de mercadorias e de superacumulação de capitais; centralização do capital e aumento das dimensões e do poder dos monopólios e do capital financeiro, com multiplicação do capital fictício; recrudescimento dos conflitos interimperialistas, do autoritarismo e da repressão; concentração de riqueza e aumento de desigualdades; crescente exploração da força de trabalho, aumento da superpopulação relativa e também da miséria e da fome; agravamento da contradição burguesia/proletariado e ofensiva burguesa em todas as frentes. Esta é a verdadeira face, cada vez menos oculta, do capitalismo atual, do putrefato sistema imperialista neste começo do século 21 (CEMFLORES, 2021, p. 2).
\end{abstract}

Potencializando a crise já existente, em 2020, a crise econômica do capital se aprofunda com a pandemia, na medida em que ocorre o fechamento do comércio, de indústrias e de empresas na busca de se efetivar um isolamento social, visando conter a disseminação do coronavírus. Essas medidas, importantes durante a pandemia, aumentaram exponencialmente o desemprego e escancararam a precarização da informalidade, mesmo que não tenham sido concretizadas de forma consistente e sólida. O governo omitiu-se de enfrentar diretamente as consequências desse processo.

Nesse contexto, o Brasil esteve com uma média de mortes diárias superior a mil no período entre o final de maio e início de agosto de 2020 (OLIVEIRA, 2020) e um aumento crescente novamente, com uma média de 3119 mortes em sete dias no período de 26 de março até 01 de abril de 2021 (BRASIL..., 2021a). Em 06 de abril, batemos o número recorde de 4211 de mortes diárias por COVID-19 (BRASIL..., 2021b). A maioria das/os especialistas da saúde acreditam que grande parte dessas mortes poderiam ter sido evitadas com medidas governamentais responsáveis.

Essa situação caótica de mortes se agravou devido à escassez de ações governamentais consonantes às propostas dos especialistas da área da saúde e da Organização Mundial da Saúde - OMS mesmo após um ano de pandemia. O isolamento social mal executado, políticas negacionistas sobre a gravidade da pandemia, somados à uma gestão incompetente na compra e distribuição de vacinas pelo Ministério da Saúde e pelo governo federal ilustram a realidade desastrosa atual. 
Ademais, destaca-se a escassez de ações governamentais visando um suporte à população de baixa renda e desempregada, sobretudo pelo cancelamento do auxílio emergencial e sua reimplantação (com muita luta por partidos da oposição) com um valor máximo de um pouco mais da metade do valor inicial de $\mathrm{R} \$ 600,00$ (CONGRESSO..., 2021). Situação caótica que só aumenta a pobreza e a fome, principalmente também pela alta no preço dos alimentos, do gás e do combustível.

Salienta-se que desde o começo da pandemia, o negacionismo é o projeto político do governo federal, em consequência, discursos que negam a gravidade da pandemia cresceram abruptamente no senso comum, reforçados também pelas notícias falsas (fake news) que circulam nas redes sociais. Dentro dessa lógica, as políticas negacionistas que não viabilizaram o isolamento social do trabalhador assalariado e dos desempregados, repercutiram em um grande número de mortos, principalmente da população negra e de baixa renda. Esse projeto eugenista e genocida dificulta lutas coletivas, a partir do irracionalismo e do conformismo, naturaliza o número de óbitos e provoca que o temor da perda do emprego, que é a base de subsistência do trabalhador, seja maior que o medo da morte por COVID-19. Pode-se ilustrar essa realidade com várias manifestações populares, que ao invés de pressionarem o governo por ampliação na vacinação, buscavam o fim do isolamento social.

Nesse cenário, mesmo diante do aumento no número de casos do coronavírus e de mortes pela COVID-19, 50\% das/os empresárias/os do país são contrárias/os ao isolamento social (DATAFOLHA..., 2021). Destarte, o empresariado fortalece e sustenta a permanência do atual governo, demonstrando assim que a efetivação da agenda neoliberal está acima de tudo, numa desvalorização da vida das/os brasileiras/os. Além disso, ainda permanece como discurso do ministro da economia e da mídia, a busca pela efetivação de mais contrarreformas, com a justificativa falaciosa de melhorar a situação, retórica que não se sustenta diante da conjuntura atual que agudiza e escancara as expressões da questão social.

A retórica da necessidade de aprovação, pelo Congresso Nacional, das contrarreformas como remédio para a calamidade pública que nos assola não se sustenta, pois, nas situações de crise profunda como a que estamos vivendo, as desigualdades sociais se tornam mais visíveis, atingindo diferencialmente burgueses e trabalhadores, ricos e pobres, centrais e periféricos (YAZBEK; RAICHELIS; SANT'ANA, 2020, p. 208).

Nesse sentido, a tragédia humanitária e sanitária se mantém por interesses políticos e econômicos. Dentre essas mortes, maioria são de pessoas acima de sessenta anos e com doenças preexistentes (NO BRASIL..., 2020), dados que repercutiram em falas como a da superintendente de seguros privados (SUSEP), que teria dito que as mortes de idosos por COVID-19 melhorariam as contas da previdência social no país (SANTOS; VENERA, 2020).

No presente âmbito caótico no qual o Brasil se encontra, é essencial que a coordenação da política nacional de saúde seja levada a sério, na execução de propostas condizentes com os especialistas da área da saúde e da OMS, e contra o negacionismo da ciência.

Não obstante, o Ministério da Saúde tem estado alinhado ao negacionismo do governo federal, na medida em que indicou tratamento precoce sem qualquer comprovação científica e não realizou logística eficiente na compra de oxigênio, insumos para vacinas e

Temporalis, Brasília (DF), ano 21, n. 41, p. 70-86, jan./jun. 2021. | ISSN 2238-1856 


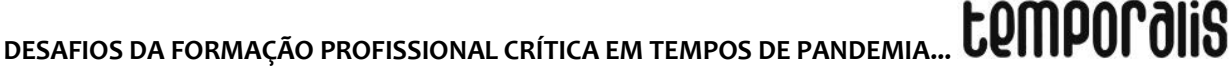

materiais para intubação, além de ter negado ofertas de compras de vacinas: da pfizer e da coronavac em 2020 (CONSELHO NACIONAL DE SAÚDE, 2021; SOBRINHO, 2021; FALTA..., 2021b; AGOSTINI, 2021; GOVERNO... 2021; MACHADO; PINHONI; FIQUEIREDO, 2021).

Posteriormente, no final de 2020 e no início de 2021, pela pressão de governadores, de prefeitos e pela mídia, o governo federal comprou essas duas vacinas e a de Oxford, com doses ainda insuficientes para toda a população, com um processo lento de vacinação e permanece com um discurso negacionista, como uma espécie de guerra aos governadores e prefeitos que estão implantando o isolamento social.

Diante desses elementos centrais que compõem a crise do capital e as consequências da pandemia da COVID-19, é primordial compreender os desafios contemporâneos da efetivação do projeto crítico de formação de Serviço Social no país.

A pandemia trouxe grandes consequências no ensino superior, como a intensificação do trabalho docente a partir das aulas remotas, que consiste numa adaptação temporária para não expor as/os profissionais e as/os discentes ao coronavírus. No entanto, tal adaptação representou a precarização do trabalho na medida em que, o/a profissional arca com todos os custos na efetivação de sua atividade laboral, somado a grande intensificação das horas de trabalho, pelo alto número de reuniões e aulas online, pela readaptação na preparação das aulas com a nova realidade e pela recorrente exaustão física e mental por horas em frente à uma tela de computador.

Do outro lado da telinha estão estudantes de graduação e pós-graduação exaustas/os, muitas vezes sem condições objetivas (como: computador, celular e internet banda larga) e subjetivas para acompanhar as aulas. Processo, portanto, que resultou também na redução na qualidade do aprendizado, frente ao cansaço e dificuldade de concentração em aulas remotas, principalmente pela quantidade de horas online e pela ausência de socialização presencial.

Ademais, salienta-se nessa nova realidade a escassez e, na maioria das universidades, a ausência de projetos de extensão dentro e fora da universidade, a utilização seletiva dos laboratórios para pesquisa e a dificultação da realização de pesquisas de campo.

É importante enfatizar a dificuldade na adaptação das aulas remotas por parte de discentes que não detém computador ou internet banda larga, somado à ausência do refeitório universitário, que constituía uma das políticas que viabilizava a permanência estudantil. Esses empecilhos repercutiram num número considerável de evasões discentes, haja vista que durante o processo de virtualização da educação, as instituições, em sua maioria, apresentaram problemáticas na análise da realidade do corpo docente e estudantil, com:

i) ausência ou baixa qualidade de diagnósticos sobre a realidade material, objetiva e subjetiva de docentes e discentes; ii) redução dos mapeamentos realizados ao aspecto do acesso à tecnologia; iii) ausência de transparência sobre os resultados dos levantamentos realizados (FARAGE, 2021, p.60-61).

Não obstante, algumas universidades, sobretudo as federais apresentaram alguns projetos e iniciativas de ampliação nos auxílios e de empréstimos de computadores. No entanto, mesmo nessas instituições, a evasão estudantil ainda pode aumentar frente ao corte

Temporalis, Brasília (DF), ano 21, n. 41, p. 70-86, jan./jun. 2021. | ISSN 2238-1856 
adicional nos recursos do governo federal de quase 20\% de 2020 para 2021 das universidades federais (CRUZ, 2021).

Destaca-se também como desafio dessa realidade pandêmica, a intensificação da jornada diária tanto de discentes como de docentes com filhas/os, sobretudo às mulheres mães. Conforme retrata Antunes (2018), ao abordar o trabalho digital e a intensificação da dupla jornada das mulheres no home office:

\begin{abstract}
nesse mundo do trabalho digital e flexível, o dicionário empresarial não para de 'inovar', em especial no setor de serviços. 'Pejotização' em todas as profissões, com médicos, advogados, professores, bancários, eletricistas, [...] Ou ainda o chamado teletrabalho e/ou home office, que se utiliza de outros espaços fora da empresa, como o ambiente doméstico, para realizar suas atividades laborativas. Isso pode trazer vantagens, como economia de tempo em deslocamentos, permitindo uma melhor divisão entre trabalho produtivo e reprodutivo, dentre outros pontos positivos. Mas com frequência é, também, uma porta de entrada para a eliminação dos direitos do trabalho e da seguridade social paga pelas empresas, além de permitir a intensificação da dupla jornada de trabalho, tanto o produtivo quanto o reprodutivo (sobretudo no caso das mulheres) (ANTUNES, 2018, p. 35).
\end{abstract}

Nesse sentido, na maioria das famílias, é para as mulheres que sobrecaem os afazeres domésticos e os cuidados com as/aos filha/os, somado ao grande número de mães solo no país. As expressões do patriarcado ficam evidentes nesse processo, agudizando-se nos prejuízos às mulheres durante a pandemia, conforme mostram os dados de diminuição na produção científica feminina em 2020 em comparação com a masculina no Brasil e no mundo. Segundo levantamento da Universidade Estadual do Rio de janeiro (UERJ) da revista Dados, os artigos submetidos no primeiro trimestre de 2020 que apresentavam mulheres na autoria era uma porcentagem de $40 \%$, esse número passou para $28 \%$ no segundo trimestre de 2020.

Vale lembrar, que falamos de uma categoria majoritariamente composta por mulheres, portanto, professoras, graduandas, mestrandas e doutorandas que se encontram nesta condição sem nenhum apoio governamental e/ou institucional.

Ademais, diante dessa manutenção das aulas remotas frente ao aumento de casos do coronavírus e mortes pela COVID-19, torna-se preocupante como será o processo do ensino a distância no país, haja vista que já estava em curso sua ampliação desde a contrarreforma do ensino superior. Ilustra-se em 2021, a regulamentação da CAPES do ensino a distância EaD para a pós-graduação stricto sensu, Mestrado e Doutorado, com a justificativa de ser uma ação necessária pelas restrições impostas pela pandemia (BRASIL, 2021). Nesse sentido, uma adaptação que era para ser momentânea, se tornou um incentivo para a ampliação do ensino remoto.

A interpelação dos desafios postos nessa conjuntura é necessária ser central nos debates do Serviço Social atualmente, para fornecer a categoria subsídios para responder as novas e as antigas demandas e, buscar estratégias no enfrentamento diante desse processo de produção e reprodução das relações sociais. 


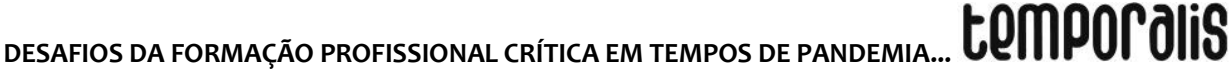

\section{CONSIDERAÇÕES FINAIS}

Diante das repercussões dessa cultura neoliberal na formação profissional em Serviço Social, que no Brasil se radicaliza numa relação direta com o conservadorismo e a pandemia, o ensino superior necessita cada vez mais afirmar o posicionamento crítico. Para isto, é essencial um vínculo orgânico entre:

[...] projeto profissional, projeto de educação e de universidade e projeto societário. Vínculo orgânico que não se estabelece no cotidiano de modo mecânico, mas mediado por um conjunto de questões e interesses que devem sinalizar para a defesa de uma educação que supõe formar pessoas para a vida, para o mundo e não somente para o exercício profissional, e para tanto pressupõe o fomento do pensamento crítico que possibilite uma ação reflexiva e competente (SOUSA; SANTOS; CARDOSO, 2013, p. 50).

Destarte, é importante o entendimento da formação como um processo informativo e formativo, no qual se compreende não só o acesso a um leque de informações, mas a formação de um sujeito social que durante a graduação possa analisar e rever suas concepções de mundo, valores e ações e, sobretudo, romper com o senso comum na compreensão do papel do Estado, da profissão, da sociedade, da questão social e dos interesses que permeiam a sociedade (SOUSA; SANTOS; CARDOSO, 2013).

Segundo lamamoto (2014), nos dias atuais, são muitos os desafios na formação profissional e é essencial: aprofundar os estudos sobre o crescente processo de mercantilização e privatização no ensino superior; defender a importância da qualificação teóricometodológica e ético-política das/os assistentes sociais frente ao aligeiramento da formação diante da subordinação aos interesses do capital; cultivar uma atitude crítica e de resistência na defesa de melhores condições de trabalho às/aos assistentes sociais e intensificar a pesquisa com os sujeitos sociais dos segmentos da classe trabalhadora levando em consideração o território, a classe social, o gênero, a etnia, a religião e a orientação sexual, priorizando abordagens que enxerguem também sua dimensão coletiva.

Destarte, é importante destacar que na busca em radicalizar a defesa de um projeto emancipatório frente ao conservadorismo, é necessário realizar uma autocrítica na categoria na forma como se expressou a apropriação da formação econômica, política e social brasileira, sobretudo na discussão da questão social. É imprescindível, numa visão de totalidade, levar em consideração a questão de classe, raça/etnia e gênero e suas mediações no processo de produção e reprodução das relações sociais. Nesse sentido, a busca por uma sociedade emancipada precisa estar pautada em conjunto com uma luta antirracista e feminista.

Ademais, ressalta-se a importância da continuidade e ampliação de debates internamente entre a categoria profissional e suas entidades, sobretudo a ABEPSS, no que tange o ensino remoto, na medida em que, essa adaptação tem ofertado precarização do trabalho docente e, simultaneamente debilitado a qualidade da formação profissional. Nesse momento, é indispensável encontrar estratégias de como continuar se posicionando em relação a temática, em oposição à ampliação do ensino à distância. A ABEPSS tem realizado essa discussão ao defender que: 
O ensino e o trabalho remotos não podem se dar à revelia de um debate que seja construído de maneira coletiva e responsável pelas comunidades acadêmicas e coletivos profissionais, de maneira a atropelar normas e regulamentações já estabelecidas (ASSOCIAÇÃO BRASILEIRA DE ENSINO E PESQUISA EM SERVIÇO SOCIAL, 2020, não paginado).

Dessa forma, a ampliação do debate que orbita em torno do ensino remoto, necessita ser realizada dentro das Unidades de Formação Acadêmicas (UFAs), no intuito de estabelecer posicionamentos éticos, políticos e abertos entendendo as dificuldades das/os discentes e docentes diante da atual realidade de precarização e buscando saídas, bem como criando resistências.

Além disso, destaca-se que dentro da realidade de ensino remoto nesse período, e, para além dele, na volta ao ensino presencial, é importante debruçar-se também nas especificidades de estudantes e docentes com filhas/os, principalmente em relação às mulheres mães. É imperiosa a necessidade das instituições desenvolverem políticas específicas que levem em consideração a temática. É necessário pensar tanto no que se refere a prazos, condições de trancamentos especiais e acesso a bolsas e auxílios a essas/es discentes, quanto no tocante a diminuição da carga horária dessas/desses professoras/es, bem como na flexibilização de critérios de avaliação para carreira docente. Destarte, pautase imprescindível o posicionamento a favor de políticas institucionais para esse público, tendo em vista o impacto das repercussões na carreira da/o docente e da/o discente referente a redução na produção científica, realidade que se intensifica sobretudo com as mulheres mães.

Portanto, na busca da efetivação de uma formação crítica em Serviço Social no Brasil hoje, cabe o enfrentamento do avanço conservador, baseando-se no pensamento crítico com responsabilidade ética e política, que, para tanto, precisa negar a base tradicional e reafirmar seu Projeto Ético Político. Dessa forma, ao lutar contra os traços conservadores é necessário criticar a formação aligeirada, acrítica e tecnicista, e defender uma formação crítica com visão de totalidade, que suscite reflexão nas/os discentes, sendo resistência às ideias simplistas de formação. E, sobretudo, saber dialogar com as/os profissionais/discentes que defendem essas ideias, enfatizando e priorizando a importância da atual hegemonia levando em consideração a questão de classe, raça/etnia e gênero.

Atualmente, é bandeira de luta do Serviço Social brasileiro a defesa de uma política de educação que tenha como referência um ensino superior público, estatal, presencial, laico, socialmente referenciado e de qualidade (ASSOCIAÇÃO BRASILEIRA DE ENSINO E PESQUISA EM SERVIÇO SOCIAL, 2019). Sigamos empunhando esta bandeira e nos encontrando nas trincheiras de maneira afetiva e resistente, acreditando sempre, que novas primaveras chegarão!

\section{REFERÊNCIAS}

ASSOCIAÇÃO BRASILEIRA DE ENSINO E PESQUISA EM SERVIÇO SOCIAL (ABEPSS).

Diretrizes Curriculares da ABEPSS. Brasília (DF), 2019. Disponível em:

http://www.abepss.org.br/diretrizes-curriculares-da-abepss-10. Acesso em: 13 mar. 2021. 


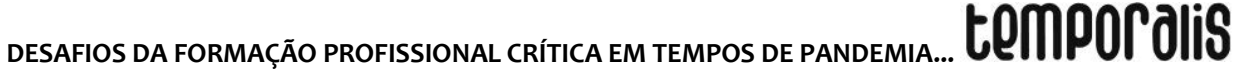

ASSOCIAÇÃO BRASILEIRA DE ENSINO E PESQUISA EM SERVIÇO SOCIAL (ABEPSS). Trabalho e ensino remoto emergencial. Notícias, ABEPSS, Brasília (DF), 23 jun. 2020. Disponível em: http://www.abepss.org.br/noticias/trabalho-e-ensino-remoto-emergencial386. Acesso em: 21 mar. 2021.

AGOSTINI, R. Governo cancelou em agosto de 2020 compra de medicamentos para kit intubação. CNN, 19 mar. 2021. Disponível em:

https://www.cnnbrasil.com.br/saude/2021/03/20/governo-cancelou-em-agosto-de-2020compra-de-medicamentos-para-kit-intubacao. Acesso em: 20 mar. 2021.

ANTUNES, R. O privilégio da servidão: o novo proletariado de serviços na era digital .1. ed. São Paulo: Boitempo, 2018.

BARROCO, M.L.S. Não passarão! Ofensiva neoconservadora e serviço social. Serv. Soc. Soc., São Paulo, n. 124, p. 623-636, out./dez. 2015.

BARROCO, M.L.S. Ética: fundamentos sócio-históricos. São Paulo: Cortez, 2008.

BOSCHETTI, I. Expressões do conservadorismo na formação profissional. Serv. Soc. Soc., São Paulo, n. 124, p. 637-651, out./dez. 2015.

BRASIL. Ministério da Educação. CAPES regulamenta polos para mestrado e doutorado EaD. Brasília (DF), 7 jan. 2021. Disponível em: https://www.gov.br/capes/pt-

br/assuntos/noticias/capes-regulamenta-polos-para-mestrado-e-doutorado-ead. Acesso em: 20 mar. 2021.

BRASIL bate marca de 3 mil mortos por Covid por dia na média móvel e soma 325,5 mil óbitos. G1, São Paulo, $1^{\circ}$ abr. 2021. Disponível em:

https://g1.globo.com/bemestar/coronavirus/noticia/2021/04/01/brasil-bate-marca-de-3-milmortos-por-covid-por-dia-na-media-movel-e-soma-3255-mil-obitos.ghtml. Acesso em: 8 jun. 2021a.

BRASIL bate marca de 4 mil mortes por Covid registradas em um dia pela $1^{\text {a }}$ vez e soma 337,6 mil na pandemia. G1, 6 abr. 2021. Disponível em:

https:/g1.globo.com/bemestar/coronavirus/noticia/2021/04/06/brasil-bate-marca-de-4-milmortes-por-covid-registrados-em-um-dia-e-soma-3376-mil-na-pandemia.ghtml. Acesso em: 8 jun. 2021.b

CONGRESSO promulga PEC que recria auxílio emergencial; lei já está em vigor. UOL, 15 mar. 2021. Disponível em:

https://economia.uol.com.br/noticias/redacao/2021/03/15/congresso-promulga-hoje-pecemergencial.htm. Acesso em: 15 mar. 2021.

CONSELHO NACIONAL DE SAÚDE (Brasil). CNS pede que Ministério da Saúde retire publicações sobre tratamento precoce para Covid-19. Brasília (DF), 19 jan. 2021. Disponível em: http://conselho.saude.gov.br/ultimas-noticias-cns/1570-cns-pede-queministerio-da-saude-retire-publicacoes-sobre-tratamento-precoce-para-covid-19. Acesso em: 20 mar. 2021. 
CRUZ, C. Corte de R\$ 1,178 bi em universidades federais vai aumentar evasão, diz presidente da Andifes. O Globo, Rio de Janeiro, 18 mar. 2021. Disponível em: https://oglobo.globo.com/sociedade/educacao/corte-de-1178-bi-em-universidadesfederais-vai-aumentar-evasao-diz-presidente-da-andifes-24930688. Acesso em: 20 mar. 2021.

CEMFLORES. Teses de conjuntura: crise, pandemia e resistências no Brasil e no mundo. [S.I.]: Cem Flores, 19 fev. 2021. Disponível em: https://cemflores.org/2021/02/19/teses-deconjuntura-crise-pandemia-e-resistencias-no-brasil-e-no-mundo/. Acesso em: 14 mar. 2021.

DAHMER, L. P. Expansão dos cursos públicos de Serviço Social entre os anos de 2003 a 2016: desafios para a formação profissional. Revista Katálysis, Santa Catarina: UFSC, v. 1, n. 21, 2018.

DATAFOLHA: 71\% dos brasileiros apoiam restrição do comércio e serviços contra a Covid19; $28 \%$ são contrários. G1, 18 mar. 2021. Disponível em: https://g1.globo.com/bemestar/coronavirus/noticia/2021/03/18/datafolha-71percent-dosbrasileiros-apoiam-restricao-do-comercio-e-servicos-contra-a-covid-19-28percent-saocontrarios.ghtml. Acesso em: 25 jun. 2021.

ENGELS, F. Do socialismo utópico ao socialismo científico. 2. ed. São Paulo: Instituto José Luís e Rosa Sundermann, 2008.

FALTA de insumos para a fabricação de vacinas contra Covid-19 preocupa. Carta Capital, São Paulo, 9 mar. 2021b. Disponível em: https://www.cartacapital.com.br/saude/falta-deinsumos-para-a-fabricacao-de-vacinas-contra-covid-19-preocupa/. Acesso em: 20 mar. 2021.

FARAGE, E. Educação superior em tempos de retrocessos e os impactos na formação profissional do Serviço Social. Serv. Soc. Soc., São Paulo, n. 140, p. 48-65, jan./abr. 2021.

GIL, A. C. Métodos e técnicas de pesquisa social. 4. ed. São Paulo: Atlas, 2002.

GOVERNO negou 3 vezes ofertas da Pfizer e perdeu 3 milhões de vacina. Carta Capital, São Paulo, 7 mar. 2021. Disponível em: https://www.cartacapital.com.br/cartaex pressa/governo-negou-3-vezes-ofertas-da-pfizer-e-perdeu-3-milhoes-de-vacina/. Acesso em: 20 mar. 2021.

HARVEY, D. O neoliberalismo: história e implicações. Tradução Adeil Sobral, Maria Stels Gonçalves. 3· ed. São Paulo: Edições Loyola, 2012.

IAMAMOTO, M. V. A formação acadêmico-profissional no Serviço Social brasileiro. Serv. Soc. Soc, São Paulo, n. 120, p. 609-639, out./dez. 2014.

IAMAMOTO, M. V. Serviço social em tempo de capital fetiche: capital financeiro, trabalho e questão social. 4. ed. São Paulo: Cortez, 2010.

IAMAMOTO, M.V.; CARVALHO, R. de. Relações sociais e Serviço Social no Brasil: esboço de uma interpretação histórico-metodológica. 11. ed. São Paulo: Cortez, 1996. 


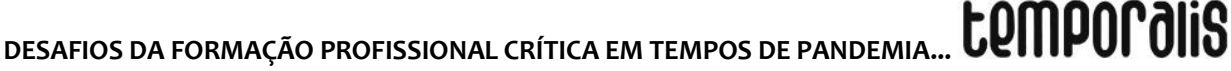

MACHADO, L.; PINHONI, M.; FIQUEIREDO, P. Ministério da Saúde ignorou três ofícios com ofertas de vacinas enviados pelo Butantã, diz diretor do instituto. G1, São Paulo, 19 fev. 2021. Disponível em: https://g1.globo.com/sp/sao-paulo/noticia/2021/02/19/ministerio-dasaude-ignorou-tres-oficios-com-ofertas-de-vacinas-enviados-pelo-butantan-diz-diretor-doinstituto.ghtml. Acesso em: 20 mar. 2021.

MELO, L. M. C.; CARDOSO, P. F. G. Pressupostos ontológicos do Ser Social: subsídios para análise crítica ao conservadorismo. In: NOGUEIRA, C. M.; GONÇALVES, R.; NOZABIELLI, S. (Org.). Trabalho, Movimentos e Políticas Sociais diálogos com o Serviço Social. São Paulo: Rosivan, 2021, p.100-101.

NETTO, J. P. Ditadura e Serviço social: uma análise do Serviço Social no Brasil pós-64. São Paulo: Cortez, 2011a.

NETTO, J. P. Introdução ao estudo do método de Marx. São Paulo: Expressão Popular, $2011 b$.

NETTO, J. P. Uma face contemporânea da barbárie. In: ENCONTRO INTERNACIONAL CIVILIZAÇÃO OU BARBÁRIE, 3., Serpa, 2010. Anais [...]. Serpa, 30-31 oct. $1^{\circ}$ nov. 2010.

NO BRASIL, maioria dos mortos por coronavírus tinha mais de 60 anos e doenças preexistentes. Folha de Pernambuco, 27 mar. 2020. Disponível em:

https://www.folhape.com.br/noticias/no-brasil-maioria-dos-mortos-por-coronavirus-tinhamais-de-60-anos-e-d/135197/. Acesso em: 25 jun. 2021.

OLIVEIRA, S. Com mais de 99 mil óbitos, Brasil tem média diária de 1.019 mortes por covid. UOL, 7 ago. 2020. Disponível: https://noticias.uol.com.br/ultimas-noticias/agenciaestado/2020/08/07/com-mais-de-99-mil-obitos-brasil-tem-media-diaria-de-1019-mortes-porcovid.htm. Acesso em: 12 mar. 2021.

SANTOS, A. B. H.; VENERA, J. I. Bolsonaro diante da verdade. Carta Capital, 18 dez. 2020. Disponível em: https://www.cartacapital.com.br/opiniao/bolsonaro-diante-da-verdade/. Acesso em: 25 jun. 2021.

SOBRINHO, W. P. Manaus: O que os governos federal, estadual e municipal fizeram de errado. UOL, São Paulo, 15 jan. 2021. Disponível em:

https://noticias.uol.com.br/saude/ultimas-noticias/redacao/2021/01/15/covid-19coronavirus-manaus-amazonas-oxigenio-governo-prefeitura-uniao.htm. Acesso em: 20 mar. 2021.

SOUSA, A. A. S.; SANTOS, S. M. M.; CARDOSO, P. Ética e Serviço Social: um itinerante caminhar. Temporalis, Brasília (DF): Abepss, n. 25, 2013.

YAZBEK; M. C.; RAICHELIS, R.; SANT'ANA, R. Questão social, trabalho e crise em tempos de pandemia. Serv. Soc. Soc., São Paulo, n. 138, p. 207-213, maio/ago. 2020. 
Priscila Fernanda Gonçalves Cardoso Trabalhou na concepção, delineamento, análise e interpretação dos dados; redação do artigo, sua revisão crítica e aprovação da versão a ser publicada.

Graduada, mestra e doutora em Serviço Social pela Pontifícia Universidade Católica de São Paulo (PUC). Professora associada da UNIFESP/BS no curso de Serviço Social e no Programa de Pós-graduação em Serviço Social e Políticas Sociais. Membra do Grupo de Pesquisa Fundamentos do Serviço Social: Ética, Trabalho e Formação da UNIFESP. Membra da coordenação do GTP de Ética, Direitos Humanos e Serviço Social da ABEPSS (gestões 2019-2020 e 2021-2022).

Giovanna Canêo Trabalhou na concepção, delineamento, análise e interpretação dos dados; redação do artigo, sua revisão crítica e aprovação da versão a ser publicada.

Assistente social formada na Universidade Federal de São Paulo (UNIFESP). Mestra em Serviço Social e Políticas Sociais pela UNIFESP. Membra da coordenação do grupo de estudos, pesquisa e extensão sociedade punitiva, justiça criminal e direitos humanos profa. Andrea Almeida Torres (GEPEX - DH - ATT) UNIFESP. Membra do Grupo de Pesquisa Fundamentos do Serviço Social: Ética, Trabalho e Formação da UNIFESP. 